\title{
In vitro study of Praecitrulus fistulosus (Stocks) Pangalo (Cucurbitaceae) fruit - A potential candidate of Anthelmintic activity
}

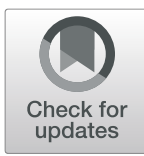

Kalpesh B. Ishnava* (D) and Karishma S. Patel

\begin{abstract}
Background: Helminthiasis infestation is one of the most widespread and severe public health problems in the world. These parasites cause several diseases like anemia, malnutrition, pneumonia, eosinophilia, and malaria. This disease is also preventable and treatable, but still, it is the major cause of death worldwide.

Results: The present study was undertaken to evaluate petroleum ether, chloroform, and methanol extract of Praecitrullus fistulosus for anthelmintic activity against Pheretima posthuma. Three concentrations (1\%, 2\%, 5\%) of each extract were taken, and these concentrations involved the determination of time of paralysis and time of death of the worms. Normal saline and albendazole were used as control and standard, respectively. The result revealed that $5 \%$ of methanol extracts of the $P$. fistulosus exhibited significant anthelmintic activity. The preliminary phytochemical analysis of crude methanol extract showed the presence of terpenoids, alkaloids, tannins, phenols, flavonoids, and glycosides. The methanolic extract was fractionated by column chromatography and the anthelmintic activity was evaluated for the different fractions and active fraction was characterization using TLC. Conclusion: These results show the isolation of active phytochemical constituent phenol, 3,5-bis (1,1-dimethyl)responsible for anthelmintic activity. Using the Pheretima posthuma as the animal models, we have shown that isolated compound from methanolic extract of fruit of $P$. fistulosus has potential to act against helminthiasis.
\end{abstract}

Keywords: Praecitrullus fistulosus, Anthelmintic activity, TLC, HPTLC, FTIR, GC-MS

\section{Highlights}

- Evaluate petroleum ether, chloroform and methanol extract of Praecitrulus fistulosus for anthelmintic activity against Pheretima posthuma.

- Petroleum ether, chloroform and methanol extract yield $9.46 \%, 10.96 \%$ and $20 \%$ respectively.

- The result revealed that $5 \%$ of methanol extracts of the $P$. fistulosus exhibited significance anthelmintic activity.

- The preliminary phytochemical analysis of crude methanolic extracts showed the presence of

\footnotetext{
* Correspondence: ishnavakb203@yahoo.com
}

Ashok \& Rita Patel Institute of Integrated Study \& Research in Biotechnology and Allied Sciences (ARIBAS), New Vallabh Vidhyanagar, Anand, Gujarat 388121, India terpenoid, alkaloids, tannins, phenol, Flavanoid and glycoside.

- Active fraction was characterization using TLC, HPTLC, FTIR, and GC-MS data.

- Isolation of active phytochemical constitution is phenol, 3,5- bis (1,1-dimethyle)- responsible for anthelmintic activity.

- Using the Pheretima posthuma as the animal models, we have shown that isolated compound from methanolic extract of fruit of Praecitrulus fistulosus has potential to act against helminthiasis.

\section{Introduction}

Helminths are huge multicellular life form which is a worm-like life form living in and benefiting from living hosts, getting sustenance and security while disturbing \\ 望 Springer Open}

(c) The Author(s). 2020 Open Access This article is licensed under a Creative Commons Attribution 4.0 International License, which permits use, sharing, adaptation, distribution and reproduction in any medium or format, as long as you give appropriate credit to the original author(s) and the source, provide a link to the Creative Commons licence, and indicate if changes were made. The images or other third party material in this article are included in the article's Creative Commons licence, unless indicated otherwise in a credit line to the material. If material is not included in the article's Creative Commons licence and your intended use is not permitted by statutory regulation or exceeds the permitted use, you will need to obtain permission directly from the copyright holder. To view a copy of this licence, visit http://creativecommons.org/licenses/by/4.0/. 
their hosts' supplement retention, causing shortcoming and malady. They can live inside the human body and different creatures. These parasites live in the human stomach related tract otherwise called intestinal parasite. Helminths are parasitic worms. They are the most widely recognized irresistible specialists of people and dairy cattle in creating nations. Helminths are perceived as a significant issue to domesticated animals all through tropics (Adewunmi et al. 2001).

In most creating nations, intestinal helminth contaminations are a significant medical issue since certain variables liable for that pre-arrange human to these diseases possess large amounts of these zones. Evaluating the worldwide weight of helminth contaminations, the two significant human irresistible ailments are related with a high death rate (Bell 1996). Elements that continue the parasite life cycles and support the expansion of the ailment vectors incorporate poor sanitation, neediness, dangerous water, lack of healthy sustenance, and numbness. In humans and pigs, $A s-$ caris has been tied to temporarily induce lactose intolerance and vitamin A, nitrogen, and fat malabsorption (WHO 1987). Weakened supplement take-up may result from direct harm to the digestive tract's mucosal dividers because of the worms' quality, yet it might likewise be an outcome of more changes, for example, synthetic irregular characteristics brought about by the body's response to the helminths (Crompton 1993). Watkins and Pollitt (1997) announced that the worms discharge protease inhibitors to shield against the body's stomach related procedure which may debilitate the breakdown of different nutritious substances too (Watkins and Pollitt 1997).

Antihelminths are drugs that expel parasitic worms from the body, by either stunning or killing them; they are also called vermifuges. The action of drug is either paralyzing or destroying the worm on contact or altering the permeability of their plasma membranes. The dead worms are removed from the body in the feces. Some drugs like albendazole, mebendazole, nicolsamide, levamisole, piperazine, and thiabendazole are used for the treatment. These drugs are generally used for the treatment of parasite infection. These drugs are not very safe and cause side effects. Recently, the use anthelmintic produces toxicity in human beings. So, the development and discovery of new substances that act as anthelmintic are being derived through plants (Piyush et al. 2013).

Restorative plants and natural products have been utilized by indigenous people groups for a considerable length of time in the treatment of assortment of irresistible illness and those brought about by parasites (Prasad et al. 2014). Various restorative plants have been utilized to treat parasitic contaminations in man and creatures (Nadkarni 1954; Chopra et al. 1956; Said 1969; Kalpesh and Priya 2020). Plants have the anthelmintic action basically due to their phytoconstituents particularly because of optional metabolites. These metabolites jointly or independently may act by hindrance of tubulin polymerization and blocking glucose take-up and harm to the mucopolysaccharide film of worms which will uncover the external layer limiting their development which at last may cause loss of motion and eventually demise of parasite (Chandrasekhar et al. 2008; Patel et al. 2010a, 2010b; John et al. 2009; Roy et al. 2010; Borba et al. 2010).

Praecitrulus fistulosus is an important plant of Cucurbitaceae which contains high amount of moisture and is rich in nutritional value. Cucurbitaceae are vegetable crops, which belong to the family Cucurbitaceae. Cucurbits are an excellent fruit in nature having composition of all the essential constituents required for good human health (Rahman 2003; Duke 1999). Cucurbits are among the largest and most diverse plant families, cultivated worldwide in a variety of environmental condition. The fruit of cucurbits is used in terms of human health, i.e., purification of blood, give energy, and removal of constipation (Kim et al. 2010). The optional metabolites are together or independently may act by restraint of tubulin polymerization and blocking glucose take-up any harm to the mucopolysaccharide film of worms will uncover the external layer confining their development which at long last may cause loss of motion and at last demise of parasite. That why this plant organic product chose for the investigation of restorative properties of Praecitrulus fistulosus for the anthelmintic movement. The accompanying goals are chosen for biological study.

\section{Material and methods \\ Collection of sample}

Praecitrullus fistulosus (Stocks) Pangalo (Tensa) fruit was collected from the local market shop of Anand, Gujarat, India, in May 2014 (Fig. 1). The fruit was identified by Dr. Kalpesh Ishnava (plant taxonomist) at Ashok and Rita Patel Institute of Integrated Study \& Research In Biotechnology and Allied Sciences (ARIBAS), New Vallabh Vidyanagar, Gujarat, India.

\section{Preparation of extract}

The collected Praecitrullus fistulosus (Stocks) Pangalo fruits were washed in distilled water, cut into small pieces, and dried under the sunlight for 3 days. After 3 days, dry sample was collected and finely powdered by using dry grinder mixer. The powder was extracted with different solvents by using solvent extraction.

\section{Hot extraction (Soxhlet extraction method)}

Fifteen grams of the dried powder of Praecitrullus fistulosus fruit material was uniformly packed into a thimble and filled the glass pot with $300 \mathrm{ml}$ different solvents separately. Solvents used were methanol, chloroform, and petroleum ether. The solvent is heated to its boiling 


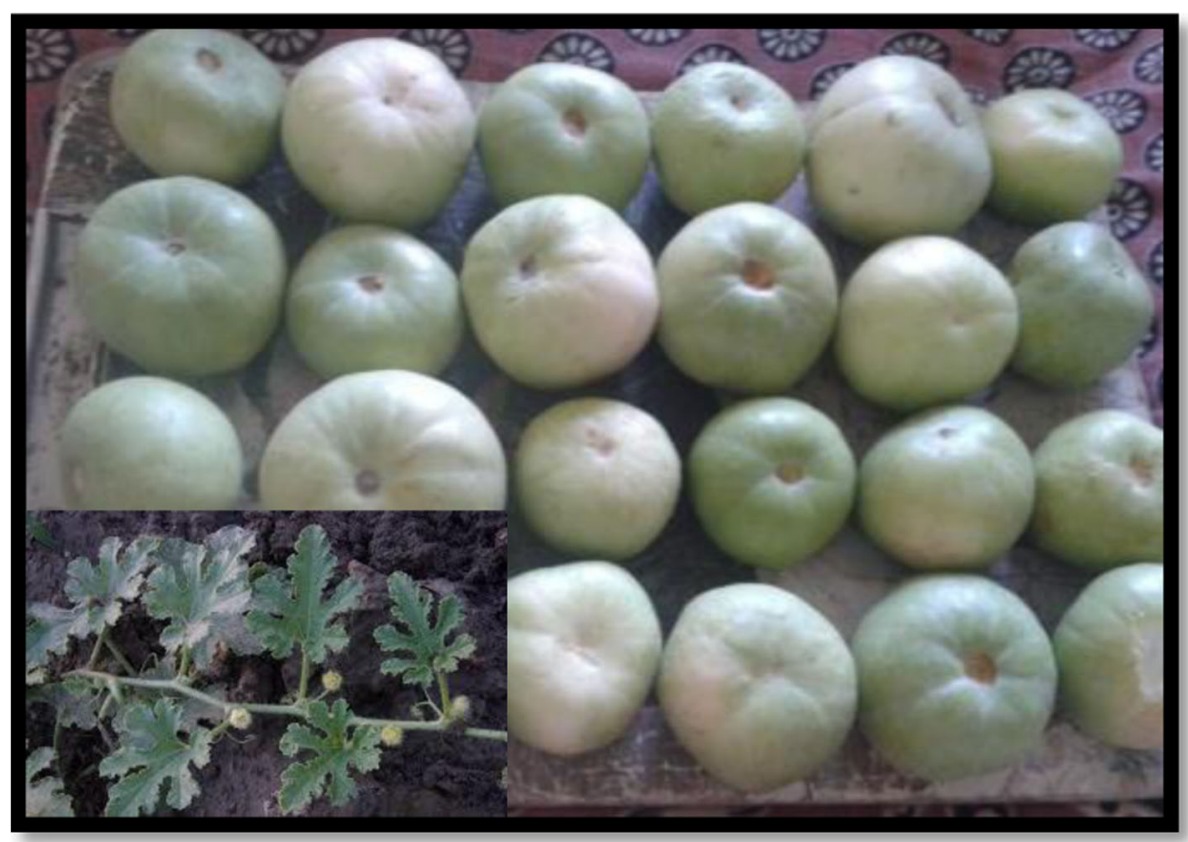

Fig. 1 Fruits of Praecitrullus fistulosus

point to reflux. Solvent vapor travels up to distillation and cool down in condenser and floods in to thimble shansing. When the Soxhlet chamber is almost full, then the chamber is automatically emptied by a side arm with the solvent running back down to the distillation pot. Cycle is allowed to repeat for $2 \mathrm{~h}$. After that, the extract was taken in a beaker. The crude extract is then filtered with a filter paper (Whatman No. 1). This filter was collected in petri plate and allowed to evaporate the solvent. After evaporation, the remaining material was collected and different stock solutions prepared by dissolving DMSO (dimethyl sulphoxide). This extract was further used for phytochemical analysis and checking the anthelmintic activity.

\section{Anthelmentic activity Biological test}

Testing animals Indian adult earthworms (Pheretima posthuma) were used to assess anthelmintic activity of fruit extracts of Praecitrullus fistulosus. Indian adult earthworm (Pheretima posthuma) was collected from moist soil of Gopalpura area of Anand District. The earthworms were washed with normal saline solution to remove all the fecal matter. The earthworms of $5-7 \mathrm{~cm}$ in length and $0.1-0.2 \mathrm{~cm}$ in width were used for all the experiment protocol.

Grouping of animals Anthelmintic activity of methanol, chloroform, and petroleum ether of Praecitrullus fistulosus was evaluated on Indian earthworms. The grouping of animals is as follows: (1) group 1, control (normal saline); (2) group 2, DMSO; (3) group 3, standard (albendazole); (4) group 4 , methanol extracts ( $1 \%, 2 \%, 5 \%$ concentrations), (5) group 5, petroleum ether extract $(1 \%, 2 \%, 5 \%$ concentrations); and (6) group 6, chloroform extract (1\%, $2 \%, 5 \%$ concentrations).

Evaluation of anthelmintic activity The anthelmintic activity was evaluated on adult Indian earthworms known as Pheretima posthuma due to their anatomical and physiological resemblance with the intestinal round worm parasites of human beings. Adult earthworms of approximately equal size were placed in petri dish that contains different concentrations $(1 \%, 2 \%, 5 \%)$ of each fruit extract solution. Observations were made for the time taken to paralysis and death of individual worms. Paralysis was said to occur when the worms do not revive in normal saline water. Death was concluded when the worms lose their motility followed with fading away of their body color.

\section{Phytochemical analysis \\ Preliminary phytochemical analysis}

Qualitative phytochemical analysis of methanolic extract of $P$. fistulosus pangalo fruits as per reported the Kalpesh et al. (2013).

\section{TLC (thin layer chromatography) technique}

Ready made plates of TLC were used in the TLC method first of all take the TLC plate $(10 \times 10) \mathrm{cm}$ as a 
stationary phase used as a silica. The TLC plate was taken, and then, a thin mark is made at the bottom of the plate with the help of a pencil. Then, sample solutions are applied on the spot marked at the line equal distance. Dry the spots using hair dryer. Take the TLC chamber. In these method as mobile phase taken Methanol: Chloroform (11:0.5) solvent system. The mobile phase (methanol to chloroform (11:0.5) solvent system) was poured into the TLC chamber to a few centimeters above the chamber bottom. The chromatographic development chamber was saturated with the mobile phase for $10 \mathrm{~min}$ prior to placement of the plates. Now, the prepared plate with sample spotting is placed in the TLC chamber and the side of the plate with sample line is towards the mobile phase. The chamber is closed with a lid. After some time, different color spots are observed on the TLC plate. Then, the plate is removed from the TLC chamber and allowed to dry. The sample spots are visualized under the UV light and iodine chamber.

\section{Colum chromatography technique}

Column chromatography is basically a type of adsorption chromatography techniques. When a mixture of mobile phase and sample to be separated are introduced from top of the column, the individual components of mixture move with different rates. These filtrates with lower affinity and adsorption to stationary phase move faster and eluted out first while those with greater adsorption affinity move or travel slower and get eluted out last. In this method, first, take out the column chromatography that requires a vertical column which is made up of glass with a knob at the bottom end. It is a burette-shaped cylindrical column. As a stationary phase, take the silica powder. This silica powder is suitably moistened with mobile phase and packed sufficiently in the column with a cotton or asbestos pad at the bottom. As a mobile phase, take the chloroform to methanol solvent system. The sample is poured into the top of the packed stationary phase with second cotton in between. The mobile phase is poured into the column over the sample and stationary phase used as silica. A collecting beaker is placed at the bottom of column near the end. In this beaker, the eluate sample was collected. After some time in the mixture of sample to be separated, different bands are observed in the column, and then, different fractions are collected. After collecting the fraction, a drop of individual fraction was spotted on the TLC plate. Separated individual component on the TLC plate was observed under the UV light and iodine chamber.

\section{HPTLC analysis}

For chemical profile analysis, the methanolic extract of $P$. fistulosus fruits (5\%) and selected active fraction was collected from column chromatography. Both extracts were concentrated to $1 \mathrm{ml}$ and used for HPTLC analysis (Camag system equipped with a sample applicator-Linomat-5, twin development chamber, TLC scanner-3 and integration software, documentation system Reprostar-3 with G5 digital camera) (Camag, Switzerland). HPTLC aluminum sheet pre-coated with silica gel 60 (1.05547 E Merck) was used as the adsorbent. Methanol to chloroform (11:0.5) was used as the mobile phase. The chromatographic development chamber was saturated with the mobile phase for $10 \mathrm{~min}$ prior to placement of the plates. The plates were run up to $8 \mathrm{~cm}$ height and derivative $(10 \%$ $\mathrm{H}_{2} \mathrm{SO}_{4}$ in methanol). The derivative plates were heated at $100{ }^{\circ} \mathrm{C}$ for $2 \mathrm{~min}$, bands were observed and scanned at 366 $\mathrm{nm}$, and photographs were taken for record.

\section{Fourier-transform infrared (FTIR) spectroscopy analysis}

A thin film of the methanolic extract of $P$. fistulosus fruits and selected active fraction collected from column chromatography in methanol was applied on the glass, and IR spectra were recorded by using a Perkin Elmer spectrophotometer, Spectrum Instrument (Germany) with FTIR paragon 1000 PC software at the Sophisticated Instrumentation Centre for Applied Research and Testing (SICART), Vallabh Vidyanagar, Gujarat.

\section{GC-MS analysis}

The GC-MS analysis was done by using the electron impact ionization (EI) method on Auto system XL gas chromatography (Perkin Elmer Instrument, Germany) coupled to a Turbo Mass Spectrophotometer (Perkin Elmer Instrument, Germany) at the Sophisticated and Instrumentation Centre for Applied Research and Training (SICART), Vallabh Vidyanagar, Gujarat. The column was fused with silica capillary column, $30 \times 0.25 \mathrm{~mm}$ ID, coated with D-I, $0.25 \mu \mathrm{m}$ film thickness. The temperature of column was programmed at 70 to $250{ }^{\circ} \mathrm{C}$ at the rate of $10^{\circ} \mathrm{C} / \mathrm{min}$ increase, injection port temperature at $250^{\circ} \mathrm{C}$. Helium was used as carrier gas at constant pressure of 100 $\mathrm{kpa}$ and flow rate of $20 \mathrm{ml} / \mathrm{min}$. Samples which were dissolved in methanol were run fully at a range of 60-550 amu, and the results were compared by using the NIST 107 Spectral library search program.

\section{Statistical analysis}

The data of anthelmintic evaluations were expressed as mean \pm SEM of three earthworms in each group. The statistical analysis was carried out using ANOVA followed by Tukey's $t$ test. The difference in values at $P$ $<0.05$ was considered as statistically significant. The analysis of variance (ANOVA) was performed using ANOVA software to determine the mean and standard error of paralysis and death time of the earthworms. 


\section{Result}

Extract yield (\%) of Praecitrullus fistulosus Pangalo fruit Fifteen grams of powder of Praecitrullus fistulosus fruit was mixed with $250 \mathrm{ml}$ of different chemicals methanol, petroleum ether, and chloroform, respectively (hot extraction). Extractive percentage yields and weight of extract are shown in Fig. 2. Maximum percentage yield of extract was obtained in methanolic extract (20\%), and minimum percentage yields of extract were obtained in petroleum ether extract $(9.46 \%)$.

\section{In vitro anthelmintic activity in Praecitrullus fistulosus Pangalo fruit}

Praecitrullus fistulosus Pangalo fruit plant material was extracted using different solvents of methanol, petroleum ether, and chloroform solvent system. Normal saline solution take as a control treated to earth worms (Pheretima posthuma) remained active with whole body movements (Table 1). 1\%, 2\% and 5\% albendazole drug used as standard treated with earth worms become shrunken and remains motile only some body parts.

\section{Preliminary phytochemical analysis of methanolic extract of $P$. fistulosus Pangalo fruit}

Phytochemical constituent analysis of methanolic extract of $P$. fistulosus fruit. In the methanolic extract, various phytoconstituents are present which are shown in Table 2. The methanolic extracts showed the presence of terpenoids, alkaloids, tannins, phenols, flavonoids, and glycosides. In this extract, saponin tests negative.

\section{HPTLC analysis of methanolic extract of $P$. fistulosus Pangalo fruit}

In the HPTLC analysis, two samples were selected for study. The first sample is A1-isolated compound by column chromatography and A2-crude extract of methanolic extract. Both samples are run in the methanol to chloroform (11:0.5) that was used as the mobile phase.

FTIR analysis of methanolic extract of $P$. fistulosus Pangalo fruit

Fourier transformer infra red (FT-IR) spectroscopy analysis (functional group were identified) was performed. We analyzed the A1 sample different peak which observed that different functional groups are present as shown in Table 3 and Fig. 3.

Gas chromatography-mass spectrometry (GC-MS) analysis of methanolic extract of $P$. fistulosus Pangalo fruit

A1 sample analyses for the identification of the compound present in the sample were used with the help of gas chromatography and mass spectroscopy. The result of the present study indicates that different peaks were observed. The peak is showing the maximum percentage area at RT 32.93 in GC-MS analysis scan through mass spectrophotometer, with the presence of phenol, 3, 5bis(1,1-Dimethyl), and the molecular weight is 206, of which at peak is 32.93. GC-MS chromatogram is shown in Fig. 4.

\section{Discussion}

This medicinal plant is a rich source of phytochemical constitutes of secondary metabolites like phenol, alkaloid, terpanoid, and glycosides. These metabolites jointly or separately may act by inhibition of tubulin polymerization and blocking glucose uptake and any damage to the mucopolysaccharide membrane of worms which will expose the outer layer restricting their movement which finally may cause paralysis and ultimately death of parasite.

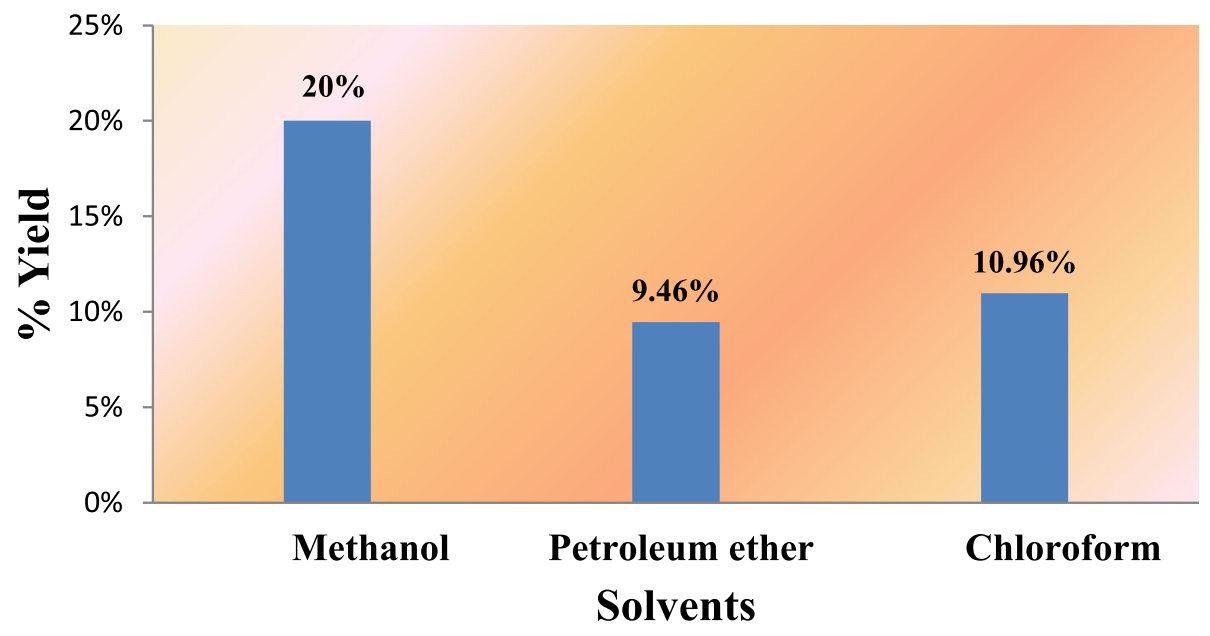

Fig. 2 Extractive yield (\%) of Praecitrullus fistulosus fruit 
Table 1 In vitro antihelminthic activity of Praecitrulus fistulosus fruit

\begin{tabular}{lllll}
\hline S.N & Group & Concentration & Time taken for paralysis (min) & Time taken for death (min), mean \pm SD \\
\hline 1 & Control & Normal saline & - & - \\
2 & DMSO & control & - & - \\
2 & Albendazole (std) & $1 \%$ & $6.13 \pm 0.0173$ & $7.26 \pm 0.057$ \\
3 & Albendazole (std) & $2 \%$ & $3.08 \pm 0.005$ & $5.01 \pm 0.017$ \\
4 & Albendazole (std) & $5 \%$ & $2.00 \pm 0.005$ & $4.03 \pm 0.015$ \\
5 & MEF & $1 \%$ & $8.00 \pm 0.011$ & $10.02 \pm 0.027$ \\
6 & MEF & $2 \%$ & $5.06 \pm 0.011$ & $6.17 \pm 0.017$ \\
7 & MEF & $5 \%$ & $3.00 \pm 0.011$ & $4.05 \pm 0.011$ \\
8 & PEF & $1 \%$ & $13.21 \pm 0.035$ & $16.02 \pm 0.026$ \\
9 & PEF & $2 \%$ & $9.18 \pm 0.035$ & $11.01 \pm 0.028$ \\
10 & PEF & $5 \%$ & $7.05 \pm 0.020$ & $8.04 \pm 0.036$ \\
11 & CEF & $1 \%$ & $16.16 \pm 0.017$ & $18.14 \pm 0.036$ \\
12 & CEF & $2 \%$ & $12.12 \pm 0.020$ & $15.04 \pm 0.041$ \\
13 & CEF & $5 \%$ & $8.34 \pm 0.025$ & $9.08 \pm 0.015$ \\
\hline
\end{tabular}

MEF methanol fraction, PEF petroleum ether fraction, CEF chloroform fraction, DMSO dimethyl sulphoxide

Extractive percentage yields and weight of extract are shown in Fig. 2. Maximum percentage yield of extract was obtained in methanolic extract (20\%), and minimum percentage yields of extract were obtained in petroleum ether extract (9.46\%). Shweta et al. (2011) reported the P. fistulosus preparation of plant fruit extract material defatted with petroleum ether $\left(60-80{ }^{\circ} \mathrm{C}\right)$ and then extracted with methanol in a Soxhlet apparatus. The percentage yield is $2.6 \% \mathrm{w} / \mathrm{w}$ and $4.7 \% \mathrm{w} / \mathrm{w}$ with respect to dried plant material in methanol. In our study, hot extraction method observed the percentage yield of methanolic extract has five times more yield.

Praecitrullus fistulosus Pangalo fruit plant material was extracted using different solvent (methanol, petroleum ether, and chloroform) systems. Normal saline solution was taken as a control treated to the earthworms (Pheretima posthuma) which remained active with whole body movements (Table 1). Using 1\% albendazole drug as a standard treatment, the earthworms become shrunken and remain motile only in some body parts, paralyzed at

Table 2 Phytochemical constituent analysis of methanolic extract of $P$. fistulosus fruit

\begin{tabular}{llc}
\hline Sr. no. & Methanolic extract & Test \\
\hline 1 & Terpenoid & + \\
2 & Alkaloid & + \\
3 & Tannin & + \\
4 & Flavanoid & + \\
5 & Saponin & - \\
6 & Phenolic & + \\
7 & Glycosides & + \\
\hline
\end{tabular}

Plus sign $(+)=$ present, minus sign $(-)=$ absent
$6.13 \mathrm{~min}$, and then finally dead after $7.26 \mathrm{~min}$. In case of $2 \%$ albendazole drug solution, the earthworms become paralyzed at $3.08 \mathrm{~min}$ and dead after $5.01 \mathrm{~min}$ (Table 1). In case of $5 \%$ albendazole drug solutions, the earthworms become slender, shrunken, paralyzed at $2.00 \mathrm{~min}$, and dead after $4.03 \mathrm{~min}$ (Table 1).

In the earthworms tretaed with $1 \%$ methanolic extract of Praecitrulus fistulosus pangalo, slow movement, paralysis at $8.00 \mathrm{~min}$, and death after $10.02 \mathrm{~min}$ were observed (Table 1). In the earthworms tretaed with $2 \%$ methanolic extract of Praecitrulus fistulosus Pangalo fruit, slight movement, paralysis at $5.06 \mathrm{~min}$, and death after $6.17 \mathrm{~min}$ were observed (Table 1). In the earthworms treated with 5\% methanolic extract of Praecitrulus fistulosus Pangalo fruit, strong paralysis at $3.00 \mathrm{~min}$ and death after $4.05 \mathrm{~min}$ (Table 1) were observed.

Shweta et al. (2011) reported the P. fistulosus methanol extract of $1 \%$ and $2 \%$ time taken for death $393.75 \pm$ $25.769 \mathrm{~min}$ and $398.75 \pm 29.324 \mathrm{~min}$, respectively. The crude extract in comparison with Soxhlet our result of methanol extracts of $1 \%, 2 \%$ and $5 \%$ time taken for death $10.02 \pm 0.027,6.17 \pm 0.017$, and $4.05 \pm 0.011 \mathrm{~min}$ respectively. This result shows all the extracts of methanol have better response to the hot extraction method compared to the Soxhlet extraction method. Shweta et al. (2011) collected the fruit from Bhopal, and our sample was collected from Gujarat. The effect of the different geographical areas also affect the yield and better activity of the extracts, and for that reason, the increase in secondary compounds gives more activity. For this reason, the collected sample of Gujarat has better activity. The Gujarat state is also a semi arid region which might be the reason the active secondary compound produce more and give more activity. Similar type of the 
Table 3 Functional group presents in methanolic extract of $P$. fistulosus fruit

\begin{tabular}{ll}
\hline Peak value frequency $\left(\mathrm{cm}^{-1}\right)$ & Functional group \\
\hline 3274.54 & Secondary amine (=NH), H-bonded (inter-molecule) \\
1644.70 & $\mathrm{C}=\mathrm{C}$ alkene stretch vibration, $\mathrm{C}=\mathrm{N}$ amine of oxides \\
1408.06 & Alkene bending vibration \\
1021.66 & Alconols, acids, anhydrides \\
709.90 & Alkene bending vibration \\
\hline
\end{tabular}

study is also reported from other authors. The methanol extracts of $A$. caudatus and $A$. viridis also exhibited dose-dependent anthelmintic activities that caused paralysis at 19.21, $14.33 \mathrm{~min}$ (at $60 \mathrm{mg} / \mathrm{ml}$ ); 12.16, $10.2 \mathrm{~min}$ (at $80 \mathrm{mg} / \mathrm{ml}$ ); and $5.75,7.8 \mathrm{~min}$ (at $100 \mathrm{mg} / \mathrm{ml}$ ), and death at 27.7, $26.6 \mathrm{~min}$ (at $60 \mathrm{mg} / \mathrm{ml}) ; 18.6,18.6 \mathrm{~min}(80$ $\mathrm{mg} / \mathrm{ml})$; and $8.5,12.7 \mathrm{~min}(100 \mathrm{mg} / \mathrm{ml})$ post-treatment. The earthworms were more sensitive to the extracts of A. spinosus, A. caudatus, and A.viridis at 60,80 , and $100 \mathrm{mg} / \mathrm{ml}$ concentrations as compared to the reference drug piperazine citrate $(10 \mathrm{mg} / \mathrm{ml})$. All the three plants' methanol extracts were more effective in causing the death of the worms as well as promoting paralysis (Ashokkumar et al. 2010). Our results in comparison with other authors proved better anthelmintic activity. This extract also showed very short time for the death of the earthworms. This different author reported different plant species compared to our result which give better activity of anthelmintic activities in the methanolic extract of $1 \%, 2 \%$, and $5 \%$. These extracts also take very short time for the death of the earthworms.

One percent petroleum ether extract of Praecitrullus fistulosus (Stocks) Pangalo fruit was treated to the earthworms which resulted to their slow movement, paralysis at $13.21 \mathrm{~min}$, and death after $16.02 \mathrm{~min}$ (Table 1). Two percent petroleum ether extract of Praecitrullus fistulosus (Stocks) Pangalo fruit was treated to the earthworms in which slight movement, paralysis at $9.18 \mathrm{~min}$, and death after 11.01 min were observed (Table 1). Five percent petroleum ether extract of Praecitrullus fistulosus (Stocks) Pangalo fruit was treated to the earthworms which resulted to strong paralysis at $7.05 \mathrm{~min}$ and death after $8.04 \mathrm{~min}$; in this case, death takes more time (Table 1 ). The results of our study showed $5 \%$ decrease in the death time of earthworms. Out of the three percentage solvents, best results and death of the earthworms within

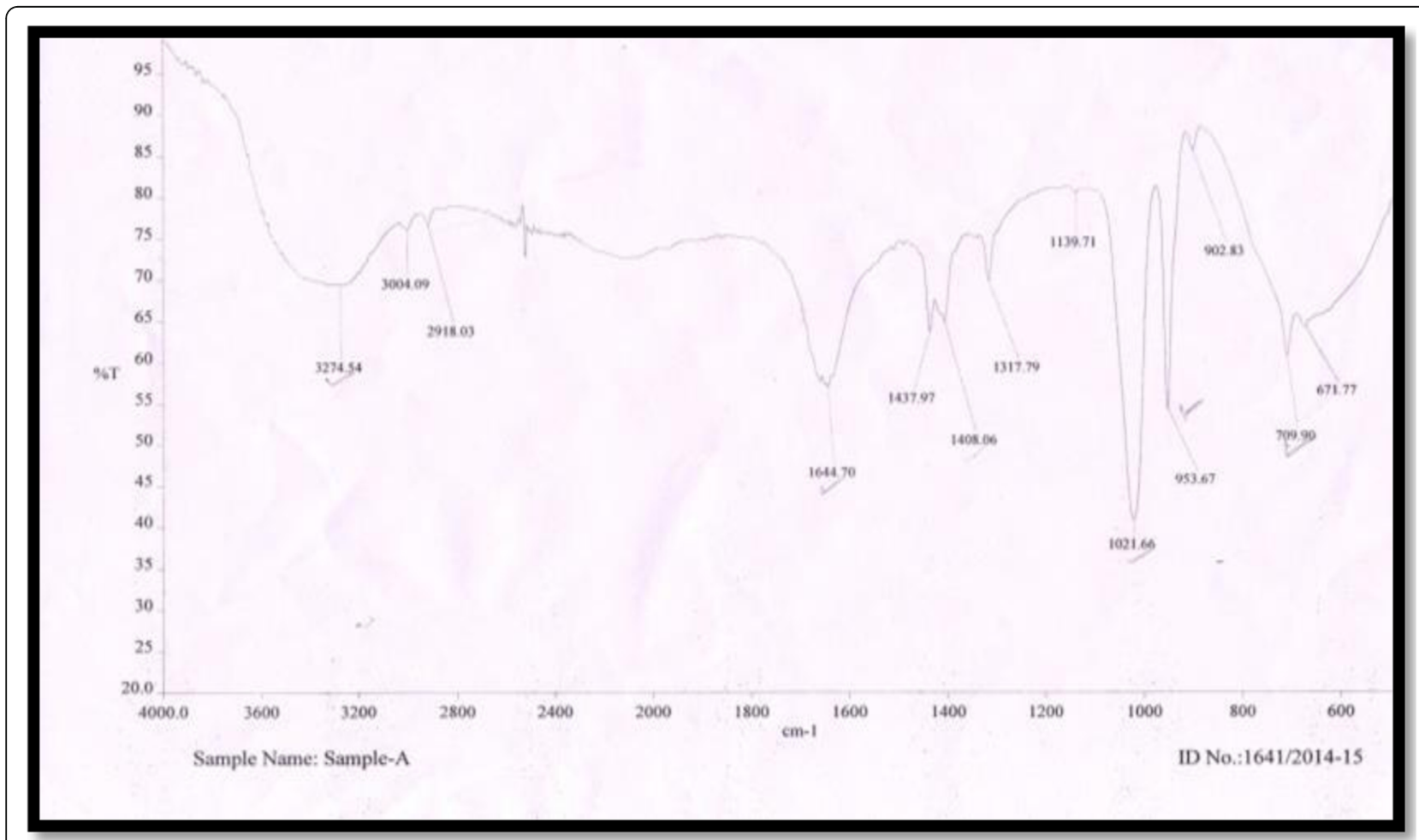

Fig. 3 FTIR analysis of methanolic extract of Praecitrullus fistulosus fruit 


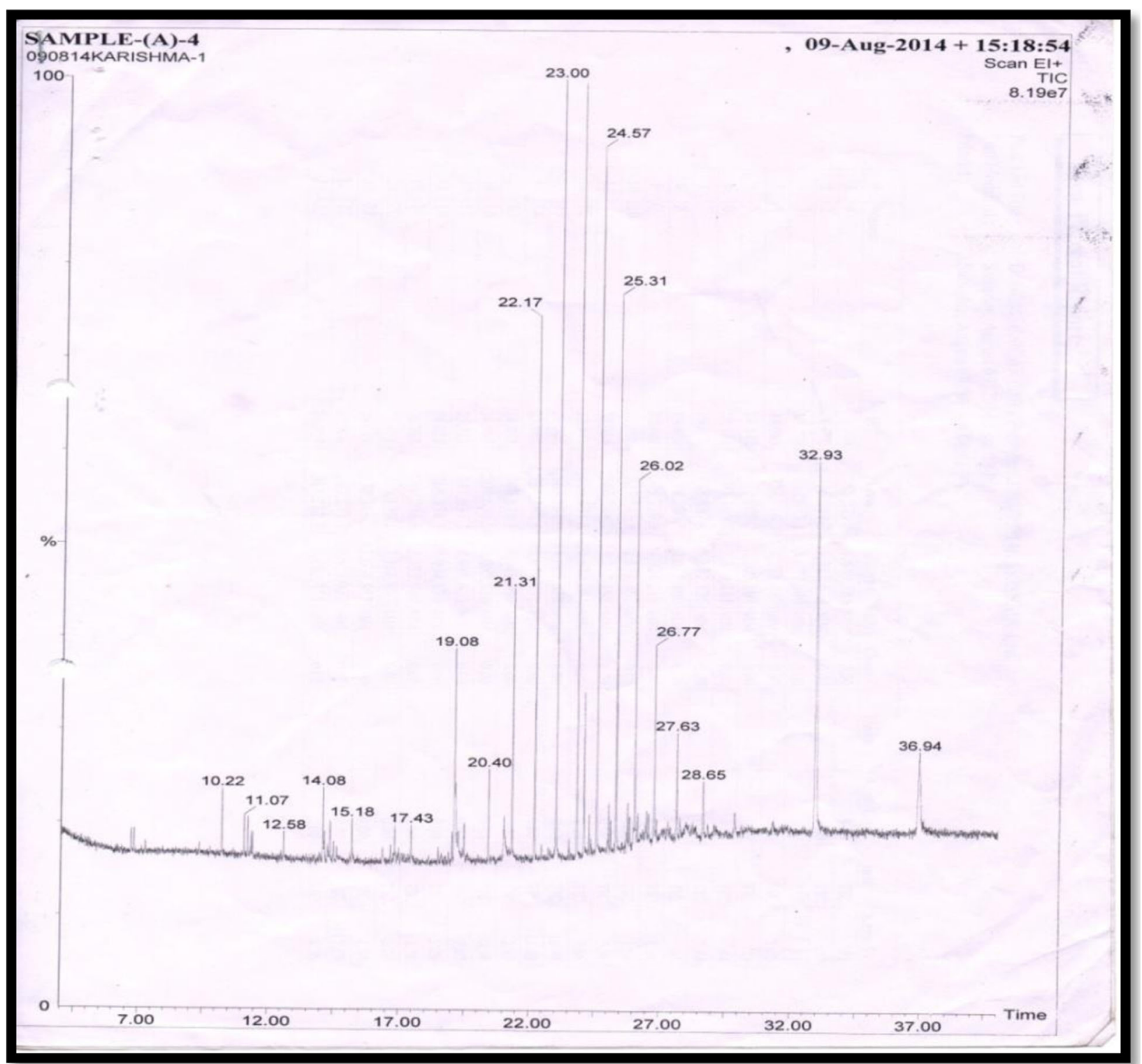

Fig. 4 GC-MS analysis of methanolic extract of Praecitrullus fistulosus fruit

a short time were observed in 5\% petroleum ether extracts compared to other percentage solvents. Shweta et al. (2011) reported the same plant fruit extract of petroleum ether extract $1 \%$ and $2 \%$. In this time taken, death takes more time. Our study shows the result compared to five times less for taken death time for earthworms. Even our study in 5\% exract times less for taken death for earthworms.

One percent chloroform extract of Praecitrullus fistulosus (Stocks) Pangalo fruit was treated to the earthworms resulting in their slow movement, paralysis at $16.16 \mathrm{~min}$, and death after $18.4 \mathrm{~min}$ (Table 1 ). Two percent chloroform extract of Praecitrullus fistulosus (Stocks) Pangalo fruit was treated to the earthworms in which slight movement, paralysis at $12.12 \mathrm{~min}$, and death after $15.04 \mathrm{~min}$ were observed (Table 1). Five percent chloroform extract of Praecitrullus fistulosus (Stocks) Pangalo fruit was treated to the earthworms which resulted to strong paralysis at $8.34 \mathrm{~min}$ and death after 9.08 min (Table 1).

All extract of (methanol, petroleum ether, and chloroform) Praecitrullus fistulosus (Stocks) Pangalo fruit showed the highest anthelmintic activity in $1 \%, 2 \%$, and $5 \%$ methanolic extract compared with chloroform extract than petroleum ether extract and albendazole. So, all study groups show the good activity observed in the 5\% methanolic extract of Praecitrullus fistulosus (Stocks) Pangalo fruit which give the best response. Based on 
these results, further detailed study on the methanol extract was needed to isolate the active compound which may be responsible for the anthelmintic activity.

Qualitative phytochemical analysis of methanolic extracts of $P$. fistulosus fruit showed the presence of terpenoid, alkaloids, tannins, phenol, flavanoid and glycoside present. The methanolic extracts showed the presence of terpenoid, alkaloids, tannins, phenol, flavanoid, and glycoside. In this extract, saponin tests negative. Shweta and Yogesh (2011) reported the same plant for the preliminary phytochemical screening of petroleum ether extract of Praecitrullus fistulosus showed the presence of alkaloids, tannins, and proteins, while methanolic extract revealed the presence of alkaloids, tannins, carbohydrates, and cardiac glycosides. Our study shows the similar type of compound present. The activities of the extract may be attributed to the presence of various secondary metabolites. Therefore, further works should be performed on the isolation and identification of the anthelmintic components in the methanoilc extract of Praecitrullus fistulosus fruit.

In the HPTLC analysis, two samples were selected for the study. The first sample is A1-isolated compound by column chromatography and A2-crude extract of methanolic extract. Both samples are run in the methanol to chloroform (11:0.5) which was used as the mobile phase. A2 sample band was observed under $254 \mathrm{~nm}$ light in TLC plate. A1 sample band was not observed under 254 $\mathrm{nm}$. A1 and A2 sample blue fluorescence band was observed under $366 \mathrm{~nm}$ UV light in the TLC plate. In the sample of A1-isolated compound by column chromatography, the Rf value is 0.74 .

Fourier-transform infrared (FTIR) spectroscopy analysis (functional group were identified) was used. We analyzed the A1 sample different peak which observed that different functional groups are present as shown in Table 3 and Fig. 3. A1 sample presents the functional group of secondary amine $(=\mathrm{NH}), \mathrm{H}$-bonded, $\mathrm{C}=\mathrm{C}$ alkene stretch vibration, $\mathrm{C}=\mathrm{N}$ amine of oxides, alkene bending vibration, acids, and anhydride group in the sample.

A1 sample analyses for the identification of the compound present in the sample were used with the help of gas chromatography and mass spectroscopy. The peak is showing the maximum percentage area at RT 32.93 in GC-MS analysis scan through mass spectrophotometer, with the presence of phenol, 3, 5bis(1,1-Dimethyl)-, and the molecular weight is 206, of which at peak is 32.93 . GC-MS chromatogram is shown in Fig. 4. The present isolated compound from the methanolic extract of Praecitrullus fistulosus fruit is phenol, 3,5-bis (1,1-dimethyl) (Fig. 5). This active compound is responsible for the anthelmintic activity. Phytochemical screening of the crude extract of Praecitrullus fistulosus revealed the presence of tannins as one of the phytoconstituents. Reported

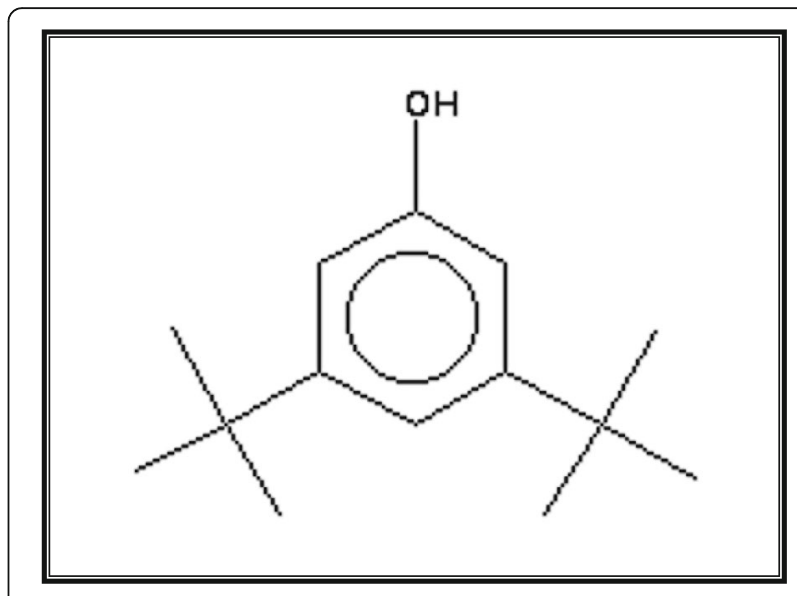

\section{Phenol, 3,5- bis (1,1- dimethyl)-}

Fig. 5 Isolated compound from methanolic extract of Praecitrullus fistulosus fruit

literature indicated that tannins are polyphenolic compounds, which showed potent anthelmintic activity (Niezen et al. 1995; Ali and Wadekar 2008; Patel et al. 2010b). The anthelmintic effect of plants depends upon the content and type of tannins (Suleiman et al. 2005). The methanol extract showed potent anthelmintic activity.

\section{Conclusion}

The present study was undertaken to evaluate petroleum ether, chloroform, and methanol extract of Praecitrullus fistulosus for anthelmintic activity against Pheretima posthuma. Petroleum ether, chloroform, and methanol extract yield $9.46 \%, 10.96 \%$, and $20 \%$, respectively. These concentrations $(1 \%, 2 \%, 5 \%)$ of each extract were taken, and these concentrations involved the determination of time of paralysis and time of death of the worms. Normal saline and albendazole were used as control and standard, respectively. This result shows that $5 \%$ of methanol extracts of the $P$. fistulosus exhibited significant anthelmintic activity. The preliminary phytochemical analysis of crude methanolic extracts showed the presence of terpenoid, alkaloids, tannins, phenol, flavanoid, and glycoside. Further methanolic extracts were fractionated by column chromatography and collect the different fractions, and each fraction checks the anthelmintic activity. Active fraction (sample a1) was characterized using TLC, HPTLC, FTIR, and GC-MS data. This result shows the isolation of active phytochemical constitution phenol, 3,5-bis (1,1-dimethyle)responsible for the anthelmintic activity. Using the Pheretima posthuma as the animal models, we have shown that isolated compound from the methanolic extract of fruit of Praecitrullus fistulosus has potential to act against helminthiasis. 


\section{Abbreviations}

TLC: Thin layer chromatography; HPTLC: High performance of thin layer chromatography; GC-MS: Gas chromatography-mass spectrometry; SD: Standard deviation; Rf: Retardation factor

\section{Acknowledgements}

The authors are thankful and acknowledge the Sophisticated Instrument Centre for Applied Research and Testing (SICART), DST, India, for HPTLC and GC-MS analyses. The authors are also thankful to Charutar Vidya Mandal (CVM), Vallabh Vidyanagar, Gujarat, India, and Director of Ashok and Rita Patel Institute of Integrated Studies and Research in Biotechnology and Allied Sciences (ARIBAS), New Vallabh Vidyanagar-388121, Gujarat, India, for providing necessary research support and laboratory facility.

\section{Authors' contributions}

Karishma S Patel-cooperation in the plan of work, field work, chemical analysis, and data arrangement; Kalpesh B Ishnava_-designing the work, interpreting the data, and writing the manuscript. Both authors read and approved the final manuscript.

\section{Funding}

Not applicable.

\section{Availability of data and materials}

Not applicable.

Ethics approval and consent to participate

Not applicable.

\section{Consent for publication}

Not applicable.

\section{Competing interests}

Not applicable.

Received: 30 March 2020 Accepted: 16 June 2020

Published online: 31 July 2020

\section{References}

Adewunmi CO, Bedahunsi JM, Adebajo AC, Aladesanmi AJ, Murphy N, Wando J (2001) Anthelmintic potential of herbal drugs. J Ethnopharmacol 77:19-24

Ali MRG, Wadekar RR (2008) In vitro anthelmintic activity of Baliospermum montanum Muell. Arg. Roots. Indian J Pharm Sci 70(1):131-133

Ashokkumar BS, Lakshman K, Jayaveera KN, Nandeesh R, Manoj B, Ranganayakulu D (2010) Comparative in vitro anthelmintic activity of three plants from the amaranthaceae family. Arch Biol Sci 62(1):185-189

Bell DR (1996) Lecture notes on Tropical Medicine, Blackwell Science, Ed. 4th, 1996 Textbook of parasitology, ISSN :81-7381-4570.

Borba HR, Freire RB, Albuquerque AC, Cardoso MEO, Braga IG, Almeida STP, Ferreira MJC, Fernandes GLT, Camacho ACL, Lima RC, Almeida ACC, Mattos DMM, Duarte RM, Nascimento SF, Framil RA, Dire GF (2010) Anthelmintic potential of herbal drugs. Nat Sci 8(4):94-100

Chandrasekhar CH, Latha KP, Vagdevi HM, Vaidya VP (2008) Anthelmintic potential of herbal drugs. In J Green Pharm:100-103

Chopra RN, Nayyar SL, Chopra IC (1956) Glossary of Indian medicinal plants. Council of Scientific and Industrial Research, New Delhi, p 160

Crompton DWT (1993) Human nutrition and parasitic infection. Cambridge University Press

Duke JA (1999) Handbook of phytochemical and constituents of GRAS herbs and other economic plants. CRC Press, Boca Raton, pp 98-119

John J, Mehta A, Shukla S, Mehta P (2009) Anthelmintic potential of herbal drugs. J Sci Technol 31(3):269-271

Kalpesh Ishnava, Jenabhai Chauhan, Mahesh Barad (2013) Anticariogenic and phytochemical evaluation of Eucalyptus globulesLabill. Saudi J Biological Science 20(1):69-74

Kalpesh Ishnava, Priya Konar (2020) In vitro anthelmintic activity and phytochemical characterization of Corallocarpus epigaeus (Rottler) Hook. f. tuber from ethyl acetate extracts. Bulletin of the National Research Centre 44:33

Kim K, Kim H, Cho H, Sakamoto N, Cheong J (2010) Curcumin inhibits hepatitis C virus replication via suppressing the Akt-SREBP-1 Pathway. FEBS Lett 584:707712
Nadkarni AK (1954) Indian Materia Medica, Vol. I, 3rd edn. Popular Book Depot, Bombay, pp 142-143

Niezen JH, Waghorn GC, Charleston WAG (1995) Growth and gastrointestinal nematode parasitism in lambs grazing either Lucerne (Medicago sativa) or Sulla (Hedysarum coronarium), which contains condensed tannins. J Agric Sci 125:281-289

Patel J, Kumar GS, Qureshi MS, Jena PK (2010a) Anthelmintic potential of herbal drugs. Int J Phytomed 2:127-132

Patel J, Kumar GS, Qureshi Md Shamim, Jena PK (2010b) Anthelmintic activity of ethanolic extract of whole plant of Eupatorium Odoratum L. Int J Phytomed 2:127-132

Piyush Jain (2013) Anthelmintic potential of herbal drugs. International Journal of Research and Development in Pharmacy and Life Sciences 2(3):412-427

Prasad Jamkhande, Amruta Wattamwar, Prakash Chandak (2014) In vitro antihelminthic efficacy of ethno-medicinal plant Annona reticulata L.roots against Indian earthworms (Pheretima posthuma). Indian Journal of Natural Products and Resource 5 (2):152-157

Rahman ASH (2003) Bottle gourd (Lagenaria ceraria) a vegetable for good health. Nat Prod Rad 2:249-250

Roy H, Chakraborty A, Bhanja S, Nayak BS, Mishra SR, Ellaiah P (2010) Anthelmintic potential of herbal drugs. J Pharmaceut Sci Technol 2(5):217221

Said M (1969) Hamdard Pharmacopea of Eastern Medicine. Hamdard National Foundation, Karachi

Suleiman Musa, Mohammed Mamman, Mohammed Aliu, Otaru Yusuf, Ajanusi Ologunja Joseph (2005) Anthelmintic activity of the crude methanol extracts of Xylopia aethiopica against Nippostrongy lus brasiliensis in rats. Veterinarski Archiv 75 (6):487-495

Shweta Gautam, Yogesh Shivhare (2011) Phytochemica screening and antioxidant potential of Praecitrullus fistulosus. Journal of Advanced Pharmacy Education \& Research 1(5):238-242

Watkins WE, Pollitt E (1997) Anthelmintic potential of herbal drug. Psychol Bull 121(2):171-191

WHO (1987) Prevention and Control of Intestinal Parasitic Infections. World Health Organ Tech Rep Ser 749

\section{Publisher's Note}

Springer Nature remains neutral with regard to jurisdictional claims in published maps and institutional affiliations.

\section{Submit your manuscript to a SpringerOpen ${ }^{\circ}$ journal and benefit from:}

- Convenient online submission

- Rigorous peer review

- Open access: articles freely available online

- High visibility within the field

- Retaining the copyright to your article

Submit your next manuscript at $\boldsymbol{\nabla}$ springeropen.com 